\title{
Concentration-dependent activities of the even-skipped protein in Drosophila embryos
}

\author{
Armen S. Manoukian and Henry M. Krause \\ Banting and Best Department of Medical Research, University of Toronto, C.H. Best Institute, \\ Toronto, Ontario M5G 1L6 Canada
}

\begin{abstract}
The Drosophila pair-rule gene even-skipped (eve) encodes a homeo-domain-containing protein (Eve) that is required for the development of both odd- and even-numbered parasegments. We have used a heat shock-inducible eve transgene to study the regulatory functions of Eve in vivo. Transcripts encoded by eight other segmentation genes were monitored for changes in distribution and abundance following short pulses of ectopic Eve expression. Two tiers of response times appeared to distinguish between genes that were direct [fushi tarazu (ftz), odd-skipped (odd), runt (run), paired, and wingless] and indirect [eve, hairy, and engrailed (en)] targets of Eve. Genes that appeared to be directly regulated by Eve were differentially repressed in a concentration-dependent fashion. Interestingly, the run and $f t z$ genes could also be activated by Eve during a brief 20- to 30-min stage in development. The delayed actions upon the eve and en genes appeared to be mediated by run and odd. As in $e v e^{-}$embryos, these effects on segmentation gene expression patterns caused defects in both odd- and even-numbered parasegments. Four sequential phenotypes could be induced, each of which was attributable to the altered expression of a unique subset of target genes.
\end{abstract}

[Key Words: even-skipped; segmentation; pair-rule genes; segment polarity genes]

Received May 1, 1992; revised version accepted June 24, 1992.

Segmentation in Drosophila is embryonically controlled by a hierarchy of interactions among several classes of genes (Nüsslein-Volhard and Wieschaus 1980; NüssleinVolhard et al. 1985). Information is relayed in a temporal progression from the coordinate genes to the gap genes, then from the gap genes to the pair-rule genes and finally, from the pair-rule genes to the segment polarity genes (for review, see Ingham 1988). The even-skipped (eve) gene is considered to be a member of the pair-rule genes (Nüsslein-Volhard and Wieschaus 1980). Weak eve mutations (hypomorphs) fit the pair-rule gene criteria, causing deletions of alternate segment-wide regions (Nüsslein-Volhard and Wieschaus 1980). Unlike the other pair-rule genes, however, eve null alleles completely abolish segmentation within the trunk of the embryo (Nüsslein-Volhard et al. 1985). Thus, eve appears to be a particularly important member of the pair-rule class of genes.

In correspondence to the severity of the eve null phenotype, eve is expressed in a dynamic fashion throughout the trunk of the embryo (Frasch et al. 1987). Low levels of uniformly distributed eve protein (Eve) resolve into an anterior-to-posterior gradient which, in turn, resolves into a 7 -stripe pattern of expression, followed by a 14-stripe pattern of expression. Eve performs both early and late functions during this 2- to 3-hr period /Goto et al. 1989|. During the time that Eve is expressed in seven stripes, it functions as a primary pair-rule gene, interpreting spatial cues provided by the gap genes and relaying this information to the other pair-rule genes (for review, see Pankratz and Jäckle 1990). Eve expression at this time defines the odd-numbered parasegmental primordia (Lawrence et al. 1987). As the Eve stripes begin to resolve, Eve is required for proper initiation of the segment polarity genes engrailed (en) (DiNardo and O'Farrell 1987; Lawrence et al. 1987) and wingless (wg) (Ingham et al. 1988) in odd-numbered parasegments. These two genes define anterior and posterior parasegmental identities, respectively.

An important issue that remains to be resolved is whether gene interactions such as these are direct or indirect. For example, is Eve a direct activator of the en gene, or does it regulate an intermediary gene whose product regulates $e n$ ? Eve contains a DNA-binding homeo domain (MacDonald et al. 1986; Hoey and Levine 1988) and functions as a sequence-specific transcriptional repressor in transfected tissue-culture cells (Han et al. 1989) and in transcriptionally competent extracts (Biggin and Tjian 1989). Although Eve appears to function exclusively as a repressor in vitro, expression patterns of several genes in wild-type and mutant embryos (see below) suggest that Eve may function as both a repressor and an activator in vivo.

We wished to distinguish between direct and indirect 
targets of Eve, and to determine whether Eve acts as a transcriptional repressor, an activator, or both. We have addressed these questions by providing short pulses of ectopic Eve expression at different stages of embryogenesis and monitoring potential Eve target genes for changes in their patterns of expression. Among the genes that we tested, those that might be direct targets of Eve repression include the pair-rule genes fushi-tarazu (ftz) (Carroll and Scott 1986; Hiromi and Gehring 1987), oddskipped (odd) (DiNardo and O'Farrell 1987; Coulter and Wieschaus 1988), runt (run) (Ingham and Gergen 1988), and paired (prd) (Baumgartner and Noll 1991), and the segment polarity gene wg (Ingham et al. 1988). Genes postulated to be directly activated by Eve include the eve gene itself (Frasch et al. 1988), the pair-rule gene hairy (h) (Ingham and Gergen 1988), and the segment polarity gene en (DiNardo and O'Farrell 1987).

The results of this study indicate that only a subset of these genes are direct targets of Eve regulatory activities. In general, our data suggest that Eve acts as a transcriptional repressor, except during its earliest stages of expression. By regulating different target genes at different developmental stages, ectopic Eve could induce four different mutant phenotypes. On the basis of these results, we suggest that Eve functions as a concentration-dependent morphogen, with sequential regulatory roles in both the odd-and even-numbered parasegments.

\section{Results}

\section{Expression of eve in HSEVE embryos}

Fly lines containing P-element-mediated insertions of a heat shock promoter (hsp70)-controlled eve gene (PHSEVE) were obtained from Gary Struhl (Columbia University; see Materials and methods). Two PHSEVE-transformed lines were used: one with the PHSEVE construct inserted into the second chromosome $\left(\operatorname{HSEVE}^{32}\right)$, and the other with an insert in the third chromosome $\left(\mathrm{HSEVE}^{19 \mathrm{~B}}\right)$. Both inserts gave equivalent results in a va- riety of different genetic backgrounds. Our first goal was to test these lines for heat shock-inducible Eve expression. Figure $1 \mathrm{~B}$ shows that $30 \mathrm{~min}$ after a short 4-min heat shock, Eve was immunologically detected in all nuclei of HSEVE embryos. Note that the underlying pattern of seven stripes was still visible, indicating that the levels of ectopic Eve were probably similar to the levels of endogenous Eve.

It has been suggested that Eve plays a direct role in the activation of its own promoter (Jiang et al. 1991). To test whether ectopic Eve could activate the endogenous eve gene, we looked at eve mRNA expression after administering 3- to 4-min heat shock pulses to embryos aged between 2 and $3 \mathrm{hr}$ after egg laying (AEL). Figure 1D shows an embryo fixed $15 \mathrm{~min}$ after the initiation of heat shock. At this time, the ectopically induced eve transcripts that had been distributed evenly over most of the embryo surface were already on the decline. In embryos fixed $30 \mathrm{~min}$ after heat shock, the heat shock-induced eve transcripts were no longer detectable (Fig. 1E). Transcripts of the endogenous eve gene, however, continued to be expressed in a relatively normal seven-stripe pattern of expression. To our surprise, in similarly staged embryos (2.5-3 hr AEL) that had been heat-shocked 45 min before fixation, eve transcripts were very weak or undetectable (Fig. IF). This autorepression was not observed if embryos were older than $2.5 \mathrm{hr}$ AEL at the time of heat shock. The 45-min delay before the loss of endogenous eve expression suggests that this repression was indirect (see below for further discussion). Thus, not only was ectopic Eve incapable of activating the endogenous eve gene outside of its normal domains of expression, but it caused a premature loss of expression within the domains in which it is normally expressed.

In this experiment and the experiments that follow, the effects described were Eve specific because extended heat shocks (up to $10 \mathrm{~min}$ ) had no effects on wild-type embryos (data not shown), and the effects of other heat shock-inducible pair-rule genes varied, depending on the

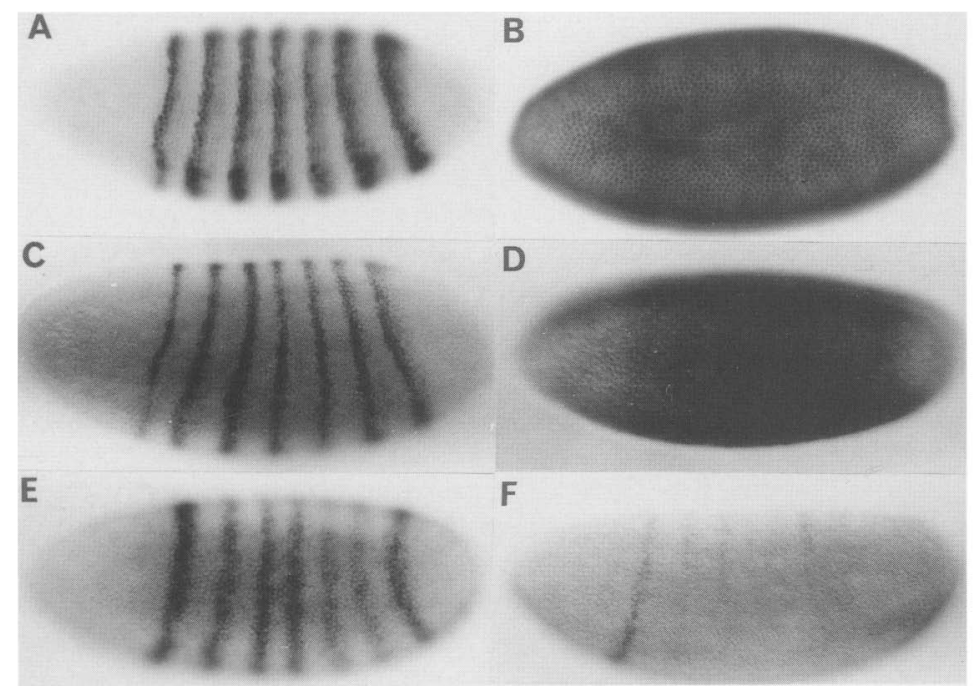

Figure 1. eve expression in HSEVE embryos. Embryos aged 2-3 hr AEL were heat shocked for $4 \mathrm{~min}$ and stained for eve protein $|A, B|$ or eve transcripts $|C-F\rangle$. $(A, C)$ Wild-type patterns of protein and mRNA, respectively. Twenty minutes after the initiation of heat shock, Eve was detected in all nuclei, with the underlying pattern of seven stripes still visible $(B) .(D-F)$ eve transcripts at $15(D), 30\langle E\rangle$, and $45(F)$ min after the initiation of heat shock. The embryos shown were all fixed at a similar developmental stage $(\sim 2.5-3 \mathrm{hr}$ AEL $)$. 
particular pair-rule gene that was induced (A.S. Manoukian and H.M. Krause, unpubl.).

\section{Repression of $\mathrm{ftz}$ by ectopic Eve}

By use of heat shock-inducible transgenes, it is possible to vary the levels of ectopic gene expression by altering the parameters of heat shock. This permits an assessment of expression levels that are functionally relevant. One of the suspected targets of Eve is the $f t z$ gene. Figure $2 \mathrm{~A}$ shows the correlation between the levels of ectopic Eve induced by different durations of heat shock and the subsequent effects on $f t z$ gene expression. Embryos aged 2.5 to $3 \mathrm{hr}$ AEL at the time of heat shock were fixed 30 min later and double-stained for Eve protein (brown) and $\mathrm{ftz}$ transcripts (blue). Consistent with the hypothesis that Eve is a repressor of the $f t z$ gene /Carroll and Scott 1986; Frasch and Levine 1987; Hiromi and Gehring 1987; Lawrence and Johnston 1989|, stripes of $f t z$ expression diminished in intensity and width as the abundance of ectopic Eve increased. Total repression of $f t z$ transcription occurred when heat shocks were $\sim 4 \mathrm{~min}$ or longer.

To address the question of whether Eve is a direct or indirect regulator of $f t z$ gene expression, we monitored the levels of Eve and $f t z$ transcripts over the course of an hour following a 4-min heat shock. A very short temporal delay between the rise in levels of Eve and the subsequent loss of $f t z$ transcripts would favor a direct interaction between the two genes. Embryos aliquoted from a common pool of heat-shocked embryos were fixed at 5to 10-min intervals following heat shock. The levels of Eve and $f t z$ transcripts in equivalent numbers of embryos were quantitated with the aid of secondary antibodies coupled to alkaline phosphatase (AP) and by monitoring AP activity colorimetrically.

Figure 2B shows that ectopic Eve expression could first be detected at 5- to $10-\mathrm{min}$ and peaked at $\sim 25 \mathrm{~min}$, after the initiation of heat shock. At their peak, the levels of ectopic Eve were approximately three to four times the levels of Eve detected in non-heat-shocked embryos for in heat-shocked wild-type embryos; not shown). If eve stripes normally occupy $20-30 \%$ of the surface of a blastoderm embryo (where the majority of nuclei are localized), this overall increase in Eve abundance by three- to fourfold should bring the interstripe levels of protein close to the levels that are expressed in the endogenous stripes. This is consistent with the levels of Eve staining in the HSEVE and wild-type embryos shown in Figure 1 (cf. A and B).

A decrease in the abundance of $f t z$ transcripts in heatshocked embryos was first detected $\sim 15 \mathrm{~min}$ after the beginning of heat shock and was essentially complete within $30 \mathrm{~min}$ of the initiation of heat shock (Fig. 2C). The estimated half-life of $f t z$ transcripts $16 \mathrm{~min}$; Edgar et al. 1986) is consistent with the rapid degradation profile of $f t z$ transcripts in HSEVE embryos depicted in Figure $2 \mathrm{C}$. If Eve is a direct repressor of $f t z$ transcription, then $f t z$ transcripts should be reduced in abundance by $50 \%$, $\sim 6 \mathrm{~min}$ after Eve reaches sufficient levels to repress the $f t z$ gene completely. In Figure 2C, it can be seen that $f t z$ expression was reduced by $50 \% \sim 23 \mathrm{~min}$ after the initiation of heat shock and that 6 min earlier $(17 \mathrm{~min}$ after the initiation of heat shock), Eve was approximately two to three times the normal levels of endogenous Eve protein. As discussed above, these levels of ectopic Eve are probably similar to or less than the levels of Eve that are normally confined to the seven stripes. Hence, these results favor the hypothesis that Eve is a direct regulator of the $f t z$ gene. Because the expression patterns of $f t z$ promoter-lac $Z$ fusion genes were also repressed within a similar time frame (data not shown), this negative regulation by Eve is likely to be mediated by regulatory elements located upstream of the ftz-coding region.

\section{Ectopic Eve acts in a concentration-dependent fashion}

To determine whether other pair-rule genes would also respond to ectopic Eve within the same time frame as $f t z$, and whether Eve would also act as a repressor of these genes, we performed whole-mount in situ hybridizations using sequences from the genes $h$, run, prd, $f t z$, and odd as probes (Fig. 3). The embryos shown were heat-shocked in a single batch for $3 \mathrm{~min}$ and fixed $30 \mathrm{~min}$ later. The only genes that were obviously affected within the 30-min recovery period, and with this duration of heat shock, were the genes $f t z$, run, and odd. All three genes were repressed but with different levels of efficiency. This dosage-dependent variation in sensitivity was also apparent when heat shocks were varied in duration (not shown). For example, heat shock durations of only 2 min did not affect $f t z$ and run expression but were still sufficient to repress odd. When the duration of heat shocks was increased to 4 min or longer, all three genes were completely repressed. Four-minute inductions also repressed the prd gene within the same 15- to 30-min recovery period /determined by visual examination only). In contrast, the $h$ and endogenous eve genes were not affected within this 30-min period, even when heat shock pulses were as long as $10 \mathrm{~min}$. These results suggest that Eve is a direct regulator of $f t z$, run, odd, and prd and that each of these genes is differentially repressed by different levels of EVE. The 30- to 45-min delay in the response time of the $h$ and endogenous eve genes suggests that they are not direct targets of Eve.

\section{Differential repression of $\mathrm{ftz}$ and odd alters en expression}

We wished to determine the consequences of the ability of Eve to repress odd at levels that did not repress $f t z$. This was tested by double-labeling for Ftz (brown) and either odd or en transcripts (blue). Before gastrulation, we found that $\mathrm{Ftz}$ and odd stripes were completely overlapping (not shown). At gastrulation, the Ftz stripes were one to two cells wider than the odd stripes (Fig. 4A). Cells that expressed Ftz and not odd were located where the $f t z$-dependent $e$ stripes initiated (Fig. 4B). The cells that express $f t z$ and en also express low levels of Eve (Frasch et al. 1987). Taken together, these observations 

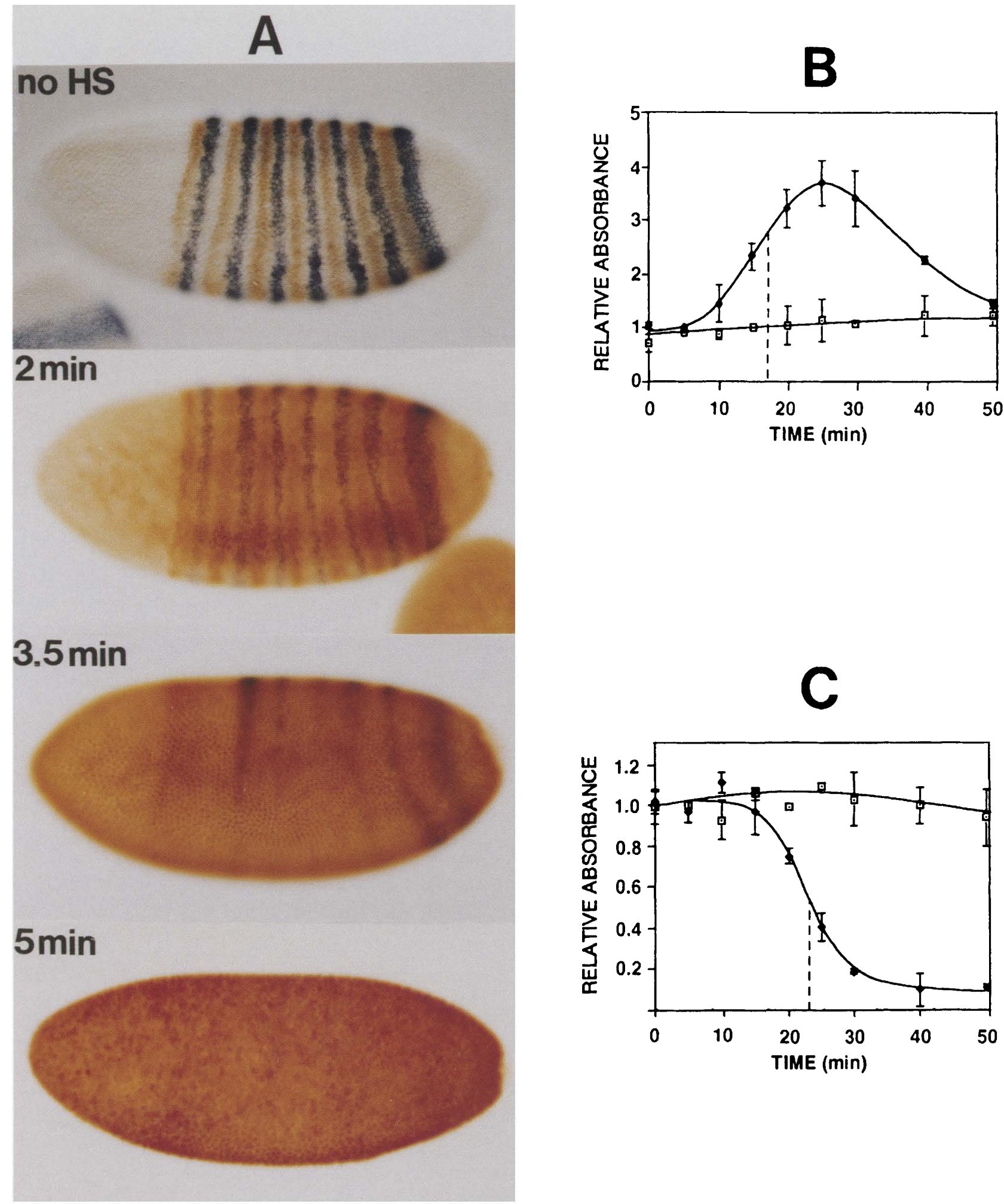

Figure 2. Effects of increasing Eve expression on $\mathrm{ftz}$. (A) Embryos shown from top to bottom were heat shocked at 2.5-3 hr AEL for $0,2,3.5$, and $5 \mathrm{~min}$, respectively, and fixed $30 \mathrm{~min}$ later. In the non-heat-shocked embryo (top), the domains of Eve (brown) and ftz mRNA (blue) were mutually exclusive. In the heat-shocked embryos, ftz stripes narrowed and disappeared as the levels of Eve expression increased. $(B, C)$ Embryos were aliquoted following a 4-min heat shock at $36^{\circ} \mathrm{C}$ and fixed at 5 -min intervals. In half of the embryos $(B)$ Eve was detected immunologically; in the other half $|C|, f t z$ transcripts were detected by whole-mount in situ hybridization. Signals were quantitated as described. Levels of AP activity are indicated ( $y$-axes) for embryos fixed at the times shown ( $x$-axes). (ㅁ) Values obtained with non-heat-shocked embryos; ( $)$ values obtained with heat-shocked embryos. These relative values were determined by dividing all $A_{405}$ values by the average of $A_{405}$ levels detected in non-heat-shocked embryos. The time after heat shock when $\mathrm{ftz}$ transcripts were diminished by $50 \%$ is indicated by a dotted line in $B$, and the abundance of Eve 6 min earlier is indicated similarly in $A$. Error bars indicate the variability in values obtained in two separate experiments. 


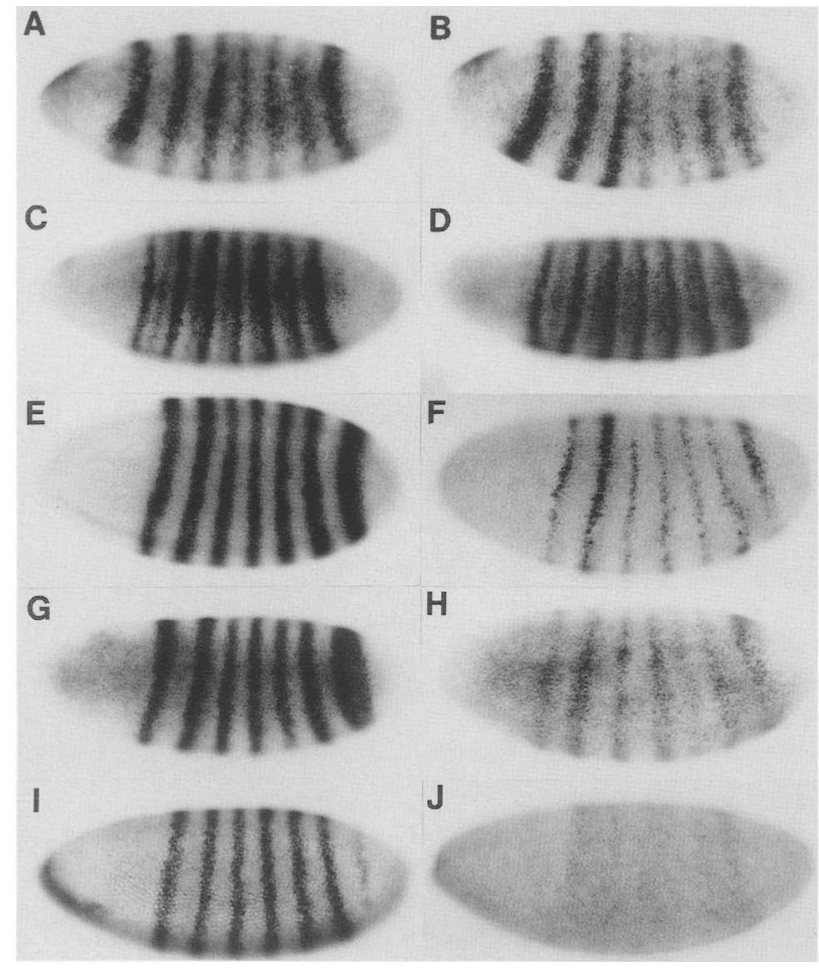

Figure 3. Dosage-dependent repression of pair-rule genes in HSEVE embryos. Whole-mount in situ hybridizations were carried out with digoxigenin-labeled probes to detect wild-type $(A, C, E, G, I)$ and HSEVE $(B, D, F, H, I)$ pair-rule gene expression patterns: $h(A, B)$; prd $(C, D)$; ftz $(E, F)$; run $(G, H)$; and odd $(I, J)$. The HSEVE embryos (right) were heat-shocked together for 3 min at $36^{\circ} \mathrm{C}$ between 2.5 and $3 \mathrm{hr} \mathrm{AEL}$, before dividing them up for hybridization with the different probes. Note the difference in sensitivities relative to the wild-type expression patterns shown at left.

suggest the possibility that $f t z$ encodes an activator of $e n$, that odd encodes a negative regulator of $e n$, and that low levels of Eve might act to repress odd so that en can be activated by Ftz.

To test this hypothesis, we attempted to induce levels of ectopic Eve that could repress odd without repressing Ftz, with the expectation that en might be activated in all Ftz-expressing cells. When HSEVE embryos were heat-shocked at $\sim 2.5 \mathrm{hr}$ AEL for $2-3 \mathrm{~min}$ and fixed 30 min later, the odd stripes that overlap with Ftz were repressed (Fig. $4 \mathrm{C}$ ). Although some $\mathrm{Ftz}$ stripes changed in width, their levels of expression were close to normal. Consequently, embryos fixed $15 \mathrm{~min}$ later expressed en in all of the $f t z$-expressing cells rather than at the anterior edges only (Fig. 4D). Hence, these data are consistent with $f t z$ encoding an activator of $e n$, odd encoding a negative regulator of $e n$, and low levels of Eve contributing to Ftz-dependent en activation through repression of odd. These results illustrate the importance of Eve concentration levels in wild-type embryos. Furthermore, they suggest that Eve may not only play an important role in the odd-numbered parasegments but in the evennumbered parasegments as well.
Eve activity varies during different stages of embryogenesis

The results presented above were obtained with embryos that were heat-shocked between 2.5 and $3 \mathrm{hr}$ AEL (at cellular blastoderm/. Because eve expression begins well before this and continues for 1-2 hr afterward, we wished to determine whether the regulatory properties of ectopic Eve would vary if induced earlier or later. Figure 5 shows the effects of ectopic Eve on the pair-rule genes $h$, odd, and run when 4-min heat shocks were administered either between 2 and $2.5 \mathrm{hr}$ AEL (beginning of cellularization) or between 2.75 and $3.25 \mathrm{hr}$ AEL (beginning of gastrulation). In each case, embryos were fixed 30 min after the initiation of heat shock to select for primary effects.

Not surprisingly, there was no effect on $h$ expression at either time, and expression of the odd gene was repressed with equal efficiency during both the early and late time intervals. In contrast, whereas the run gene was repressed with late heat shocks, it was ectopically activated with early heat shocks. This ectopic activation during early embryogenesis was also observed with $f t z$, although it was not as extensive and was restricted to a shorter time interval (data not shown). Because this early activation was complete within the same time interval that $f t z$, run, odd, and prd had been repressed by later heat shocks, we also classified it as a primary response. This suggests that Eve may be capable of acting as both a repressor and an activator, depending on the stage of embryogenesis and the gene being regulated.

\section{Effects of ectopic Eve on en and wg expression}

Initiation of expression of the segment polarity genes en and $w g$ begins at the time that eve changes from a $7 \cdot$ to a 14-stripe pattern of expression ( - 3-3.5 hr AEL). The 14 en stripes overlap with the 14 eve stripes, and wg stripes appear as the seven wide eve stripes begin to narrow. The nature of these overlaps, taken together with the loss of all en stripes and the widening of wg stripes in eve amorphs, suggests that eve may be a positive regulator of en and a negative regulator of $w g$. We induced ectopic Eve expression at the time that en and $w g$ expression are normally initiated to address the question of whether these interactions are direct or indirect. Figure 6 shows embryos stained for either en or wg transcripts $30 \mathrm{~min}$ after the initiation of a 4-min heat shock. No effect was observed on the initiating pattern of en expression in the presence of ectopic Eve. In contrast, repression of $w g$ transcripts was observed as early as $15 \mathrm{~min}$ and was complete within $30 \mathrm{~min}$ of heat shock, even with heat shock pulses as short as $2 \mathrm{~min}$. These criteria suggest that Eve is a direct and potent repressor of wg expression and that it is not a direct regulator of $e$.

\section{Ectopic Eve generates four mutant phenotypes}

Changes in the patterns of en expression were only observed with recovery times in excess of $30 \mathrm{~min}$. These 


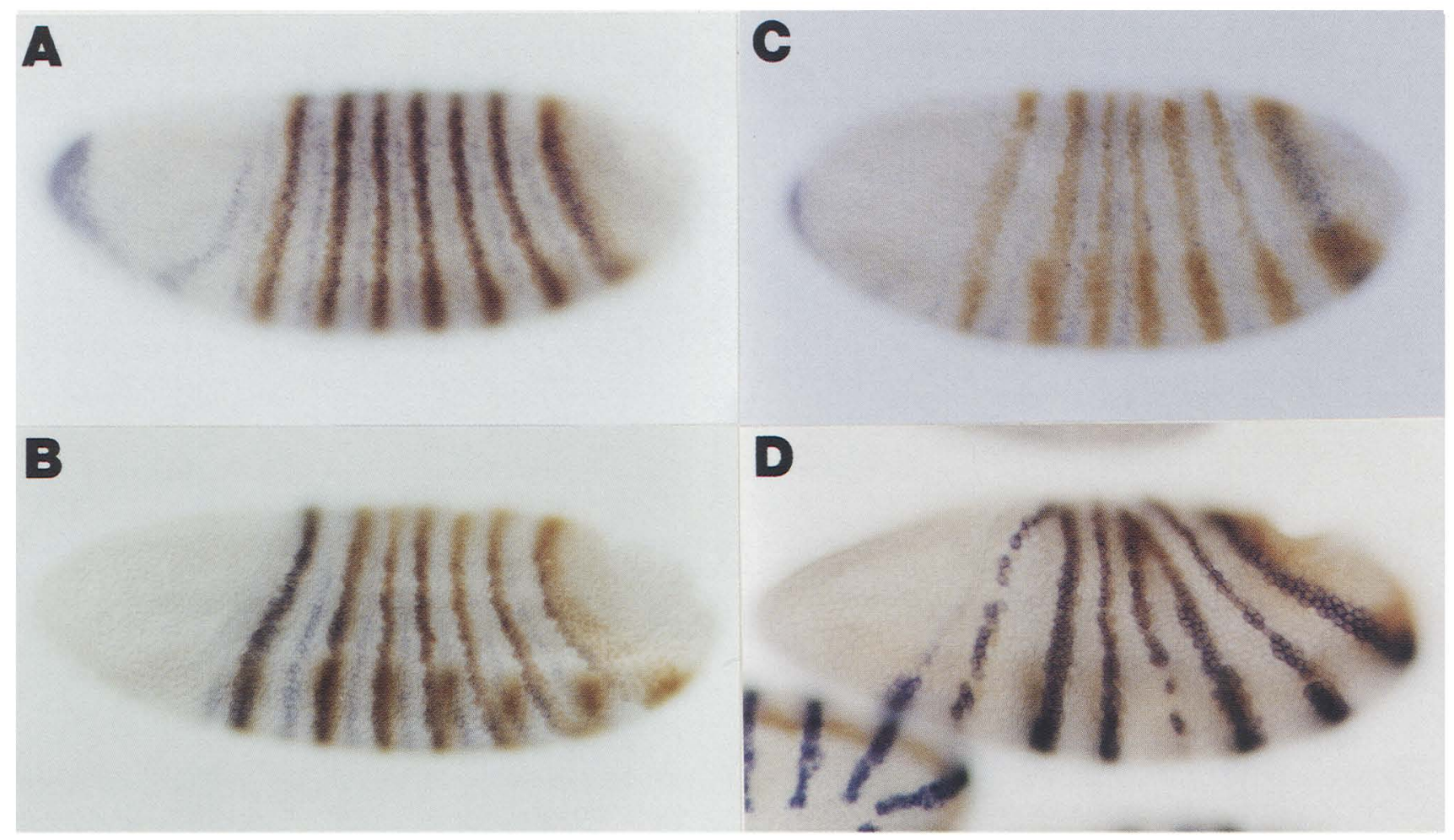

Figure 4. Differential repression of $f t z$ and odd is important for en expresion. Embryos were double-stained for $f t z$ protein (Ftz) (brown) and either odd $(A, C)$ or en $(B, D)$ transcripts (blue). $(A, B)$ Wild-type embryos fixed at 3.25 and $3.5 \mathrm{hr}$ AEL; $(C, D)$ similarly staged HSEVE embryos fixed 45 and $60 \mathrm{~min}$ after heat shock. Note that the odd transcripts (blue) that overlap with Ftz in $A$, are absent in $C$. Consequently, en transcripts that partially overlap with Ftz stripes in $B$ are completely overlapping with Ftz in $D$.

delayed changes in en expression patterns varied, depending on the timing of ectopic Eve induction. Four different patterns were observed when heat shocks were administered between 2 and 3.5 hr AEL. Heat shocks within this $1.5 \mathrm{hr}$ interval also generated four different segmental phenotypes that were evident in preparations of mature embryo cuticles. Figure 7 shows each of the four en expression patterns and the corresponding cuticular phenotypes.

The embryos shown in the left-hand panels of Figure 7 (A-E) were double stained for en protein $(E n)$ and wg transcripts at 5.5-6 hr AEL. At this stage, the patterns of En (brown) and $w g$ (blue) are indicative of the cuticular phenotypes that will ensue. The patterns shown are also indicative of the early patterns of En and $w g$ that we observed at $3.5 \mathrm{hr}$ AEL (data not shown). In wild-type embryos, 14 evenly spaced stripes of En can be seen, each with a stripe of $w g$ immediately in front (Fig. 7A). Each $\mathrm{En} / \mathrm{wg}$ interface represents a parasegmental boundary. The odd-numbered En stripes mark the anterior boundaries of the "eve-dependent" (odd-numbered) parasegments, and the even-numbered En stripes mark the anterior boundaries of the "ftz-dependent" (even-numbered) parasegments.

When embryos were heat-shocked between $2 \mathrm{hr}$ and 2 $\mathrm{hr}$ and $20 \mathrm{~min}$ AEL, the odd-numbered En stripes shifted posteriorly (Fig. 7B). Closely juxtaposed En stripes tended to fuse together, forming a single stripe of En with a single stripe of $w g$ in front (e.g., stripe $3 / 4$ in Fig. $7 \mathrm{~B})$. This fusion of En stripes was observed more frequently with stronger heat shocks $(>3 \mathrm{~min})$ and in embryos fixed at later stages of development. The regions that were deleted by these fusions corresponded to the odd-numbered (eve-dependent) parasegments. This is in agreement with the pair-rule cuticular phenotype shown in Figure 7G. The regions still remaining in this cuticle correspond to the even-numbered ( $f t z$-dependent) parasegments.

Heat shock pulses of 2-3 min administered at $2 \mathrm{hr}$ and 20 to $2 \mathrm{hr}$ and $40 \mathrm{~min}$ AEL generated the novel pattern of En and wg stripes shown in Figure 7C. Seven wide En stripes were flanked on both sides by stripes of wg expression. This pattern resulted from widening of the even-numbered ( $f t z$-dependent) En stripes, as shown previously in Figure 4, and loss of the odd-numbered En stripes. Seven wide stripes of $w g$ appeared between the widened stripes of $\mathrm{En} \sim 1 \mathrm{hr}$ after heat shock (not shown) and then split, leaving two narrow stripes adjacent to the En stripes on either side (Fig. 7C). This generated a pattern of mirror-image symmetries in which lines of symmetry passed, either down the center of each En stripe or midway between each En stripe. With stronger heat shocks, all En stripes narrowed and then disappeared, with the narrowest stripes disappearing first. 


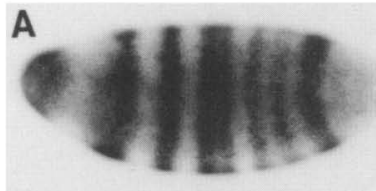

C

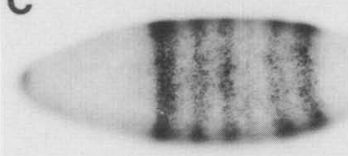

E

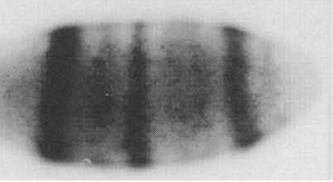

B

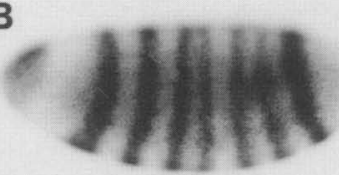

D

$\mathbf{F}$

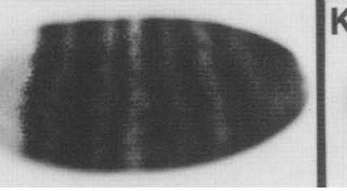

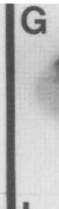

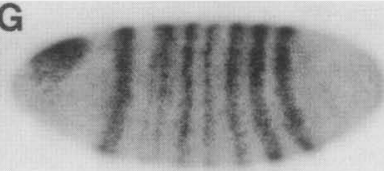

H

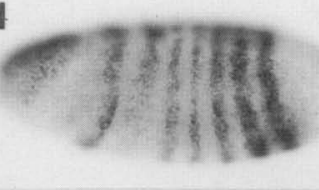

J

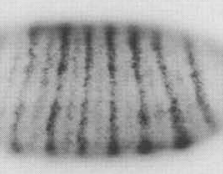

K

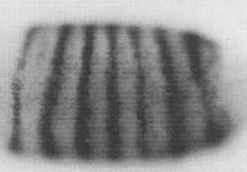

L

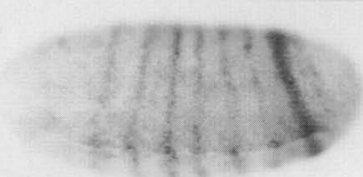

Figure 5. Eve regulatory activities vary at different stages of embryogenesis. Embryos aged at either $2.5(A-F)$ or $2.75-3.25(G-L)$ hr AEL were heat shocked for $3 \mathrm{~min}$ and fixed $30 \mathrm{~min}$ after the initiation of heat shock. Embryos in the top row show in situ detection of $h$ transcripts $(A, B, G, H)$; embryos in the middle row were probed for odd transcripts $(C, D, I, I)$; and embryos in the bottom row were probed for run transcripts $(E, F, K, L)$. Wild-type expression patterns $(A, C, E, G, I, K)$ are shown to the left of each heat-shocked embryo $(B, D, F, H, I, L)$.

The corresponding cuticular phenotype (Fig. $7 \mathrm{H})$ also exhibited patterns of mirror-image symmetry. With weak heat shocks, the odd-numbered abdominal denticle belts were replaced by mirror-image duplications of the first one or two rows of denticle belt bristles, and the even-numbered denticle belts were replaced by duplications of one or two rows of posterior denticle belt bristles. Stronger heat shocks caused further deletions of first the anterior and then the posterior denticle belt duplications, leaving only naked cuticle (not shown).

The third pattern of En and wg (Fig. 7D) was much like the 2-hr to 2-hr and 20-min AEL pattern. Heat shocks administered between $2 \mathrm{hr}$ and $40 \mathrm{~min}$ and $2 \mathrm{hr}$ and 50 min AEL also caused pairing and fusion of En stripes. However, in this case, fusions were between En stripes 2 and 3, 4 and 5, etc. Whereas the odd-numbered En stripes appeared to shift posteriorly in the early pattern, they appeared to shift anteriorly in this pattern. As might be expected, a pair-rule cuticular phenotype, which was the opposite of the 2-hr to 2-hr and 20-min phenotype, resulted (Fig. 7I). In this case, the even-numbered ( $f t z$-dependent) parasegments were deleted.

The fourth mutant phenotype occurred when heat shocks were administered at $2 \mathrm{hr}$ and $50 \mathrm{~min}$ to $3 \mathrm{hr}$ and 20 min AEL. In contrast to the earlier heat shocks, wg expression generally failed to initiate and did not reappear at later stages of embryogenesis (Fig. 7E). This repression of $w g$ was probably not a factor with earlier heat shocks owing to the removal of ectopic Eve before the time that wg expression was normally initiated. Although En stripes initiated normally with heat shock pulses at this time, they began to disappear shortly afterward. This gave rise to a cuticular phenotype (Fig. 7J), which appeared to be the opposite of the $2-\mathrm{hr}$ and $20-\mathrm{min}$
Figure 6. Transcription of the segment polarity genes $e n$ and $w g$ in wild-type and HSEVE embryos. The expression patterns of en $|A|$ and $w g$ $|C|$ in wild-type embryos at the onset of expression are highlighted by 14-stripe transcription patterns. The en-expressing embryos shown are slightly older than the wg-expressing embryos because en expression is initiated shortly after wg. In HSEVE embryos, which were fixed $30 \mathrm{~min}$ after the initiation of a 4-min heat shock, en expression was unaffected $(B)$ while wg expression was repressed $(D)$.
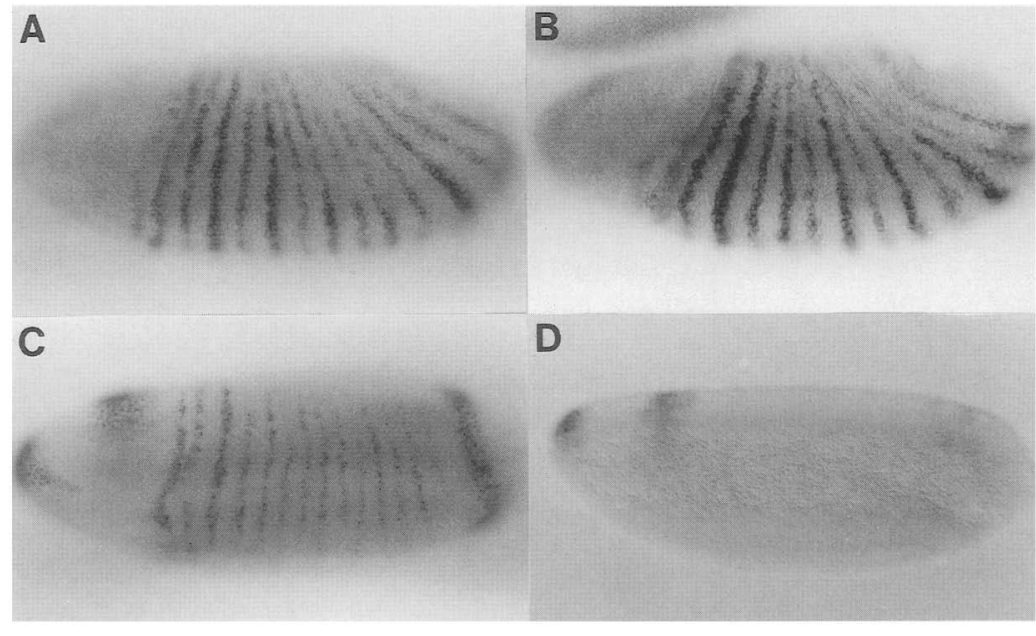


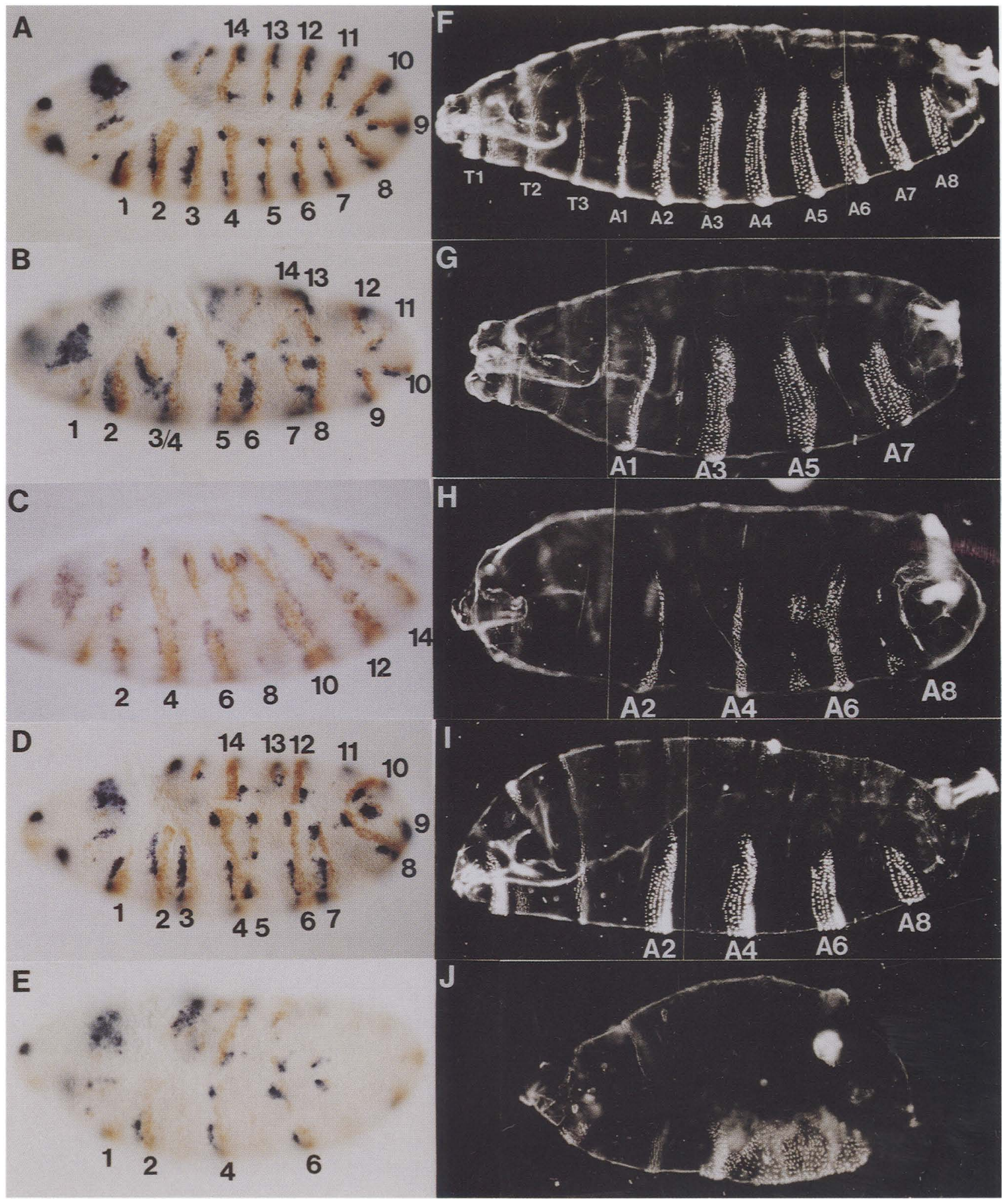

Figure 7. Effects of ectopic Eve on segmental patterning. Embryos were double-stained for en protein (En), and wg transcripts in HSEVE embryos were fixed at 5.5-6 hr AEL $(A-E)$. The different En/wg patterns are as follows: $(A)$ Wild-type En/wg expression; $(B)$ embryo heat-shocked for $4 \mathrm{~min}$ at $2 \mathrm{hr}$ to $2 \mathrm{hr}$ and $20 \mathrm{~min} \mathrm{AEL} ;(C)$ embryo heat-shocked for $3 \mathrm{~min}$ at $2 \mathrm{hr}$ and $20 \mathrm{~min}$ to $2 \mathrm{hr}$ and 40 min AEL; $(D)$ embryo heat-shocked for $3 \mathrm{~min}$ at $2 \mathrm{hr}$ and $40 \mathrm{~min}$ to $2 \mathrm{hr}$ and $50 \mathrm{~min} \mathrm{AEL} ;(E)$ embryo heat-shocked for $3 \mathrm{~min}$ at $2 \mathrm{hr}$ and $50 \mathrm{~min}$ to $3 \mathrm{hr}$ and $10 \mathrm{~min} \mathrm{AEL}$. Corresponding cuticle patterns $|F-J|$ are shown for larvae that received heat shocks at the same stages as the embryos shown at left: No heat shock $(F)$; heat shock between $2 \mathrm{hr}$ and $2 \mathrm{hr}$ and $20 \mathrm{~min}$ AEL $(G) ; 2 \mathrm{hr}$ and $20 \mathrm{~min}$ and $2 \mathrm{hr}$ and $40 \mathrm{~min}(H) ; 2 \mathrm{hr}$ and $40 \mathrm{~min}$ and $2 \mathrm{hr}$ and $50 \mathrm{~min}(I)$, and $2 \mathrm{hr}$ and $50 \mathrm{~min}$ and $3 \mathrm{hr}$ and $20 \mathrm{~min}(J)$. The abdominal denticle belts are numbered. Note that germ band extension was retarded by Eve induction at $2 \mathrm{hr}$ and $20 \mathrm{~min}$ to $2 \mathrm{hr}$ and $40 \mathrm{~min} \mathrm{AEL}(\mathrm{C})$. 
to 2-hr and 40-min AEL phenotype; instead of naked cuticle, these embryos yielded lawns of denticles.

\section{Discussion}

Null mutations of eve disrupt both odd- and even-numbered parasegments. Our results with a heat shock-inducible eve transgene indicate that Eve provides multiple regulatory cues in both sets of parasegments and that these functions are sequential. The window of time during which ectopic Eve generated segmental phenotypes-1.5 hr-is considerably longer than the 15- to 30 min window of sensitivity obtained with the pair-rule gene $f t z$ (Struhl 1985), and can be subdivided into four phases, each characterized by a specific phenotype. The segmental phenotypes caused by earlier Eve inductions were apparent reciprocals of those generated by later inductions. These phenotypes and their apparent reciprocity can be rationalized in terms of the observed effects on the expression of downstream target genes.

\section{Direct vs. indirect targets of Eve regulatory activities}

By providing short pulses of Eve expression and following the levels of potential target gene products, we distinguished two different response times. Changes in the expression patterns of five of the eight genes tested ( $\mathrm{tz}$, run, odd, prd, and $w g$ ) could be detected within $15 \mathrm{~min}$ of a short 2- to 4-min heat shock and were complete within 30 min of heat shock. The remaining three genes leve, $h$, and $e n$ ) showed a delayed response between 30 and 45 min of ectopic Eve induction. A quantitative analysis of Eve and $f t z$ expression levels following heat shock indicated that the rapid 15 - to 30 -min response time was consistent with a direct regulatory interaction between the two genes. A similar response time observed with $f t z$ promoter-lac $Z$ fusion genes indicates that this negative regulation was mediated via sequences located upstream of the $f t z$-coding region. The other four genes that responded within the same 15- to 30-min interval may also be direct targets of Eve, whereas the three genes that responded later are probably not.

These response times may be of general use in distinguishing between other direct and indirect gene interactions, although several caveats must be considered. For example, heat shocks are believed to alter rates of transcription and translation. Interestingly, we did not observe any obvious effects on the expression of genes monitored in this study (even with 15- to 20-min heat shocks). Translation of ectopic eve transcripts also appeared to be unaffected by heat shock, as ectopic Eve accumulated at a constant rate, even during heat shocks as long as $1-2 \mathrm{hr}$ (data not shown). We did, however, note short delays in development that were proportional to the duration of heat shock. These were minimal with the 2- to 4-min heat shocks used in this study. Another consideration is the size and half-life of transcripts being monitored. In this study all of the transcripts were similarly sized, and those that have been tested have similar half-lives (Edgar et al. 1989). Another concern is that some proteins may be active at very low levels of expression. This would shorten the time that is necessary between successive gene interactions.

\section{Regulation of the en and eve genes}

The loss of en and eve transcripts in eve mutant embryos had suggested previously that Eve could be a direct activator of these two genes (DiNardo and O'Farrell 1987; Frasch et al. 1988). However, their delayed response to ectopic Eve argues against this possibility. Our results with en indicate that Eve may activate it indirectly by repressing other repressors. One candidate is the product of the odd gene, because Eve rapidly repressed odd, and this repression was followed by activation of $e n$ in cells that had expressed odd previously. This indirect circuitry is also consistent with the observation that half of the 14 en stripes that disappear in $e v e^{-}$embryos reappear in $e v e^{-} /$odd $d^{-}$double mutant embryos (DiNardo and O'Farrell 1987). The reappearance of only the evennumbered en stripes in eve-/odd ${ }^{-}$embryos suggests that Eve represses other negative regulators of $e n$ in the odd-numbered parasegments. One of these may be the product of the run gene, because ectopic run rapidly represses the odd-numbered en stripes (first and second phenotypes; A.S. Manoukian and H.M. Krause, in prep.) and Eve was a potent repressor of run (after $2.5 \mathrm{hr}$ AEL).

The lack of a direct response to ectopic Eve by the endogenous eve gene was more of a surprise. In eve embryos, stripes of expression driven by the eve promoter fail to resolve normally and are then lost prematurely (Frasch et al. 1988). Jiang et al. (1991) proposed that this regulation was direct because they identified a regulatory element upstream of the eve transcription start site that contained Eve-binding sites and required eve gene activity. To abolish this eve-dependent activity, all Eve-binding sites within a truncated form of the element had to be destroyed. Jiang et al. (1991) favored redundancy of these sites to explain the need to remove them completely. Our data suggest that Eve acts indirectly by regulating the expression of an intermediary gene. The product of this gene may no longer be capable of regulating the extensively mutated element constructed by Jiang and co-workers. As with en, run is a candidate for such a gene, because run appears to be a negative regulator of eve (Ingham and Gergen 1988; A.S. Manoukian and H.M. Krause, in prep.) and ectopic Eve was an effective repressor of run. Alternatively, the failure of ectopic Eve to activate the endogenous eve gene in the interstripe regions might be explained by the absence of a necessary cofactor or by the presence of an overriding repressor.

\section{Eve as a concentration-dependent morphogen}

In wild-type embryos, the levels of Eve vary dramatically. Initially, expression is very low and then resolves into an anterior-to-posterior gradient. Following their formation, the seven stripes polarize with the highest levels of expression at the anterior edges. Finally, at the 
14-stripe phase, the stripes alternate between weak and strong. Our results indicate that these different levels determine the scope of target gene regulation. Each of the five genes that Eve repressed responded to a different level of the ectopic protein: odd and $w g$ by very low levels of Eve, $f t z$ and run by intermediate levels, and prd only by very high levels. The importance of this differential regulation was demonstrated effectively by the relative balance between the levels of Eve, $f t z$, and odd and the subsequent effects on en expression. With low levels of Eve, the loss of odd allowed expansion of the even-numbered en stripes into all $f t z$-expressing cells. At slightly higher levels of Eve, $f t z$ was also repressed and en expression was lost altogether.

\section{Possible roles for Eve as a transcriptional activator}

In addition to acting as a dosage-dependent repressor, Eve had the apparent ability to act as a temporally restricted activator. When Eve was induced before cellularization ( $2 \mathrm{hr}$ to $2 \mathrm{hr}$ and $20 \mathrm{~min}$ AEL), ftz and run were activated ectopically rather than being repressed. The rapid response of these two genes suggests that this activation was direct. Examples of transcription factors that can act as both activators and repressors include the proteins PRTF (pheromone/receptor transcription factor), which regulates yeast haploid cell mating type ('Tan and Richmond 1990|, and the glucocorticoid receptor (Diamond et al. 1990). In both cases, the basic activity of these proteins could be altered by specific interactions with other proteins. In a similar fashion, Eve may sometimes act as a gene-specific transcriptional activator as well as a repressor, perhaps through specific interactions with different stage- and promoter-specific factors.

\section{Changing regulatory roles of the eve gene}

Each of the four phenotypes generated by ectopic Eve is summarized in Figure 8 . The similarities of these phenotypes to known pair-rule and segment polarity mutant phenotypes, taken together with changes in the expression patterns of these genes upon Eve induction, suggest possible mechanisms for each phenotype. We attribute the reciprocity of the first and third phenotypes to the respective loss of either the $e v e$ - or $f t z$-dependent parasegments. Loss of the eve-dependent parasegments appeared to be caused by indirect repression of the endogenous eve gene and the odd-numbered stripes of en owing to the ectopic activation of run. Loss of the ftzdependent parasegments in the third phenotype is probably the result of the direct repression of $f t z$. The second and fourth phenotypes also retained either the even-or odd-numbered parasegments, respectively. However, unlike the first and third phenotypes, they were subject to mirror-image duplications owing to the widening or loss of $e n$ and wg stripes. In the 2-hr and 20-min to 2-hr and 40-min phenotype, en stripes expanded owing to the repression of $o d d$. Expansion of wg was probably the result of the expansion of run and the subsequent repression of eve. In contrast, the fourth phenotype appeared to be

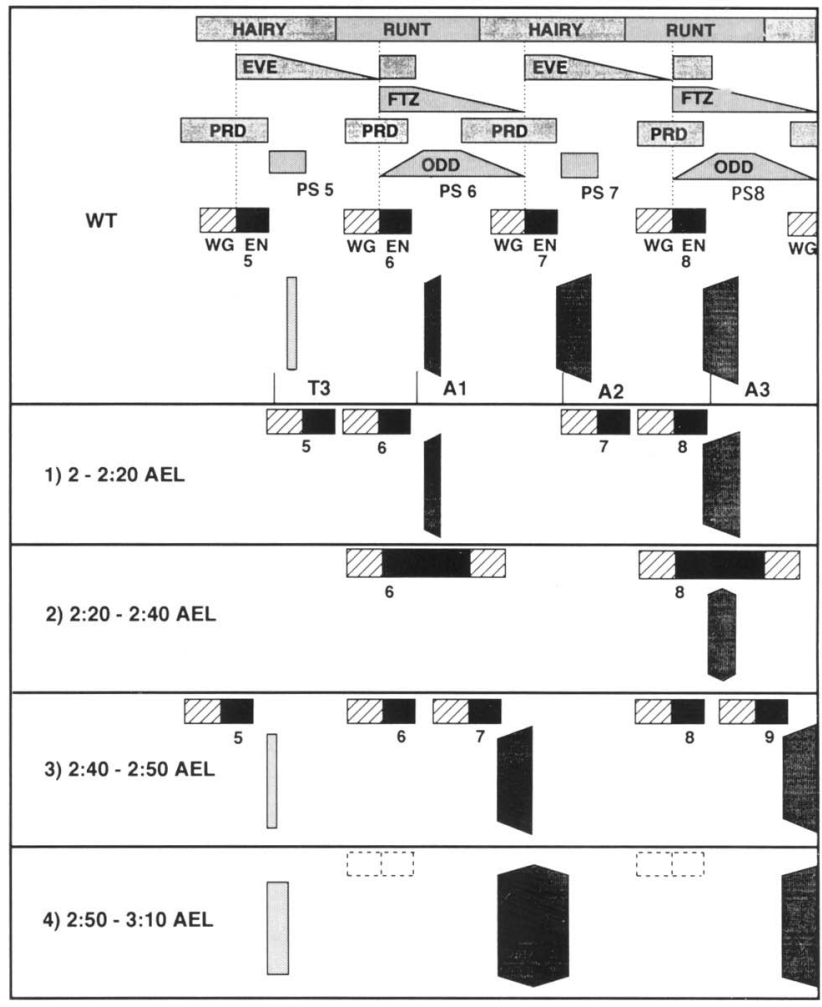

Figure 8. Summary of En/wg expression patterns and associated cuticle patterns in HSEVE embryos. The top panel portrays the approximate expression patterns of the segmentation genes addressed in this study between parasegments (PS) 5 and 8 . The borders of each parasegment are defined by the juxtaposition of $e n$ and $w g$ stripes (denoted by dotted lines). Segmental borders and ventral denticle belt features are shown at the bottom of the panel. The wedge-shaped stripes of eve, $f t z$, and odd denote the narrowing of these stripes that occurs during gastrulation. The narrow stripes of eve and odd that appear at gastrulation are shown as unlabeled boxes. (Panels 1-4) The four mutant En/wg and cuticle patterns that evolved in HSEVE embryos and the times at which they occurred.

caused by the direct repression of $w g$ and the subsequent loss of en, which has been shown to be wg dependent during early stages of expression (Martinez-Arias et al. 1988; Heemskerk et al. 1991).

These experiments suggest that the endogenous eve gene is required to perform multiple regulatory roles in both the odd- and even-numbered parasegments. The earliest role of Eve may be to assist in the activation of run and $f t z$, as evidenced by its ability to activate these genes ectopically. Shortly thereafter, Eve appears to act as a repressor of these two genes as well as odd, thereby establishing the odd-numbered parasegments. The narrowing of the seven Eve stripes then permits $w g$ expression at the posterior edges of the odd-numbered parasegments. Initiation of en stripes follows at the 14-stripe phase of Eve expression, with the 7 weaker stripes of Eve required to repress odd in the even-numbered parasegments and higher levels to repress both odd and run in the odd-numbered parasegments. 


\section{Opposing roles of Eve and Ftz}

Although Eve and Ftz define reciprocal sets of parasegments, Eve appears to function primarily as a transcriptional repressor, whereas in vitro and tissue culture studies suggest that Ftz acts as a transcriptional activator (Jaynes and O'Farrell 1988; Han et al. 1989; Winslow et al. 1989; Okhuma et al. 1990). In the embryo, both genes are positive regulators of $e n$ and negative regulators of wg. Perhaps Ftz performs these functions in a manner that is complementary to that of Eve, acting as a direct activator of $e n$ and an indirect repressor of $w g$.

Clearly, transcriptional repressors can control patterning as effectively as transcriptional activators. Gene regulation by repressors may be particularly suited to genes that are activated by ubiquitous or broadly expressed activators. This would allow many different genes to be activated by a few widely distributed activators and resolved into complex patterns by specific repressors. This may be the case for most of the genes that are regulated by Eve.

\section{Materials and methods}

\section{Construction and transformation of PHSEVE}

Construction of the plasmid PHSEVE and P-element transformation of flies were performed by Gary Struhl. Briefly, a HinfI restriction site located $21 \mathrm{bp}$ upstream of the eve ATG and an SspI site located $50 \mathrm{bp}$ downstream of the eve translation stop site were used to isolate the eve-coding region (for eve sequence, see MacDonald et al. 1986). After the addition of EcoRI linkers, the eve sequence was inserted into a vector that contains an hsp70 promoter and tubulin gene $3^{\prime}$-untranslated sequences (Struhl 1989). The hsp70-eve-tubulin hybrid gene was inserted into Carnegie 20 and transformed as described previously (Struhl 1989).

\section{mRNA and protein localization}

In general, embryos were collected in cylinders over a 30-min interval and aged appropriately at $25^{\circ} \mathrm{C}$ before fixation. When correct staging of the embryos was critical, embryos were collected for $20 \mathrm{~min}$ and visually staged under halocarbon oil (Wieschaus and Nüsslein-Volhard 1986). The detection of transcripts in embryos was achieved by whole-mount in situ hybridization with the modifications described by Edgar and O'Farrell (1990). Antibody staining procedures were as described previously (Krause et al. 1988), except that PBTB (PBS buffer $+0.1 \%$ Tween 20 and $1 \%$ dry milk powder/ was used for blocking and antibody incubations, and biotinylated secondary antibodies were detected with the Vectastain kit /Vector Laboratories). In general, double antibody/in situ stainings were performed as described, with in situ hybridizations done before the antibody stainings. Alternatively, antibody detection was performed first by using PBTH /filter-sterilized $1 \times$ PBS $+0.1 \%$ Tween $20,100 \mu \mathrm{g} / \mathrm{ml}$ of heparin, $100 \mu \mathrm{g} / \mathrm{ml}$ of tRNA, 0.05 $\mathrm{U} / \mathrm{ml}$ of RNasin) instead of PBTB, followed by in situ hybridization as described. All embryos were mounted in $80 \%$ glycerol, $20 \mathrm{~mm}$ Tris ( $\mathrm{pH} 7.5$ ). Embryos in which signals were detected by AP staining were subjected to dehydration in $90 \%$ and $100 \%$ ethanol, to remove background staining and to change the signal from purple to blue, and then rehydrated before mounting.

\section{Protein and RNA measurements}

Embryos for kinetic experiments were collected on apple juice plates that were placed in population cages for $30 \mathrm{~min}$. The embryos were then aged for $2.5 \mathrm{hr}$ at $25^{\circ} \mathrm{C}$, transferred to glass coverslips, covered with a thin layer of glycerol to distribute heat evenly, and heat-shocked by floating the coverslips on water for $4 \mathrm{~min}$ in a $36^{\circ} \mathrm{C}$ water bath. Embryos were then dechorionated and divided into equal portions. These were maintained at $25^{\circ} \mathrm{C}$ and fixed at appropriate intervals following heat shock. Protein or mRNA localization was carried out as described with secondary antibodies that were coupled to AP, and with the following modifications. Just before enzymatic detection, embryos were washed once in diethanolamine buffer $[10 \mathrm{~mm}$ diethanolamine ( $\mathrm{pH} 9.5$ ), $0.5 \mathrm{mM} \mathrm{MgCl}{ }_{2}$ ]. The number of embryos per reaction was normalized by adding the equivalent of $50 \mu \mathrm{l}$ of settled embryos to $0.5-\mathrm{ml}$ microcentrifuge tubes. The reactions were developed by rocking for $1 \mathrm{hr}$ at $25^{\circ} \mathrm{C}$ in $400 \mu \mathrm{l}$ of $\mathrm{AP}$ reaction mix [a 5-mg tablet of $p$-nitrophenyl phosphate (PNP, Sigma) dissolved in $10 \mathrm{ml}$ of diethanolamine buffer]. Reactions were stopped by adding an equal volume of $100 \mathrm{mM}$ EDTA, and activity was determined by measuring the $A_{405}$ of each supernatant. We found that activities were linear with respect to time during the 1 -hr incubation period and that anywhere from 10 to $100 \mu \mathrm{l}$ of settled embryos gave proportional signals. At the end of the 1-hr period, embryos were recovered, washed in the usual AP staining buffer and then stained with the insoluble AP substrates 5-bromo-4-chloro-3-indolyl phosphate (BCIP) and nitroblue tetrazolium (NBT). The AP reactions with PNP in diethanolamine had no detrimental effects on RNA or protein localization within embryos.

It was also possible to extract much of the insoluble purple AP substrate produced by the NBT/BCIP reaction from the embryos with $100 \%$ ethanol. This was performed by rinsing the embryos once in $100 \%$ ethanol and then extracting for $1 \mathrm{hr}$ with occasional shaking at $65^{\circ} \mathrm{C}$ in $200 \mu \mathrm{l}$ of ethanol. The ethanol was then diluted with $300 \mu \mathrm{l} \mathrm{H}_{2} \mathrm{O}$, and absorbance was measured at a wavelength of $550 \mathrm{nM}$. Quantitative results obtained by this method were similar to those obtained by using the soluble AP substrates. We found that for the soluble PNP reactions, antibodies that gave a weaker signal gave a more linear result. For Eve detection we used anti-Eve monoclonal antibodies obtained from N. Patel (Carnegie Institution of Washington). The ethanol extraction technique worked best with strong signals such as those generated with a polyclonal anti-Eve antibody obtained from $M$. Frasch. A higher percentage of the BCIP/ NBT product could be ethanol extracted if the embryos were stained lightly rather than heavily.

\section{Cuticle preparations}

Embryos were collected for $20 \mathrm{~min}$ on apple juice plates and aged appropriately. Heat shocks were performed by transferring the embryos to glass coverslips, covering them with a thin layer of halocarbon oil, and floating the coverslips on water in a $36^{\circ} \mathrm{C}$ water bath. Following heat shock, embryos were examined under the microscope, and properly staged embryos were transferred to apple juice plates. After $24 \mathrm{hr}$ at $25^{\circ} \mathrm{C}$, unhatched embryos were dechorionated and then dissected from their vitelline membranes in Hoyer's medium (Wieschaus and Nüsslein-Volhard 1986). Clearing was carried out for 2-3 days at $65^{\circ} \mathrm{C}$ in Hoyer's medium.

\section{Acknowledgments}

We thank Gary Struhl for graciously providing us with his HSEVE lines and for communicating his initial results. Many thanks go to N. Patel and M. Frasch for providing Eve antibodies, P. Gergen for providing run and prd cDNAs, D. Coulter for providing odd cDNA, and S. Coté for wg cDNA. We also thank D. Coulter, J. Greenblatt, C.J. Ingles and the reviewers for help- 
ful comments on the manuscript and M. Levine for providing encouragement and helpful suggestions. This work was supported by grants from the Medical Research Council (MRC) of Canada and the National Cancer Institute (NCI) of Canada. A.S.M. was supported with funds from the NCI and the Canadian Cancer Society, and H.M.K. was supported by a MRC of Canada Scholarship.

The publication costs of this article were defrayed in part by payment of page charges. This article must therefore be hereby marked "advertisement" in accordance with 18 USC section 1734 solely to indicate this fact.

\section{References}

Baumgartner, S. and N. Noll. 1991. Network of interactions among pair-nule genes regulating paired expression during primordial segmentation of Drosophila. Mech. Dev. 33: 118.

Biggin, M. and R. Tjian. 1989. A purified Drosophila homeodomain protein represses transcription in vitro. Cell 58: 433-440.

Carroll, S. and M. Scott. 1986. Zygotically active genes that affect spatial expression of the fushi tarazu segmentation gene during early Drosophila embryogenesis. Cell 45: 113126.

Coulter, D.E. and E. Wieschaus. 1988. Gene activities and segmental patterning in Drosophila: Analysis of odd-skipped and pair-rule double mutants. Genes \& Dev. 2: 1812-1823.

Diamond, M.I., N.M. Jeffrey, S.K. Yoshinaga, and K.R. Yamamoto. 1990. Transcription factor interactions: Selectors of positive or negative regulation from a single regulatory element. Science 249: 1266-1272.

DiNardo, S. and P. O'Farrell. 1987. Establishment and refinement of segmental pattern in the Drosophila embryo: Spatial control of engrailed expression by pair-rule genes. Genes \& Dev. 1: 1212-1225.

Edgar, B. and O'Farrell, P. 1990. The three postblastoderm cell cycles of Drosophila embryogenesis are regulated in G2 by string. Cell 62: 469-480.

Edgar, B., M. Weir, G. Schubiger, and T. Kornberg. 1986. Repression and turnover pattern of fushi tarazu RNA in the early Drosophila embryo. Cell 47: 747-754.

Edgar, B., G. O'Dell, and G. Schubiger. 1989. A negative switch based on negative regulation sharpens stripes in Drosophila embryos. Dev. Genet. 10: 124-142.

Frasch, M. and M. Levine. 1987. Complementary patterns of even-skipped and fushi-tarazu expression involve their differential regulation by a common set of segmentation genes in Drosophila. Genes \& Dev. 2: 981-995.

Frasch, M., C. Rushlow, H. Doyle, and M. Levine. 1987. Characterization and localization of the even-skipped protein of Drosophila. EMBO I. 6: 749-759.

Frasch, M., R. Warrior, J. Tugwood, and M. Levine. 1988. Molecular analysis of even-skipped mutants in Drosophila development. Genes \& Dev. 2: 1824-1838.

Goto, T., P.M. Macdonald, and T. Maniatis. 1989. Early and late periodic patterns of even-skipped expression are controlled by distinct regulatory elements that respond to different spatial cues. Cell 57: 413-422.

Heemskerk, J., S. DiNardo, R. Kostriken, and P.H. O'Farrell. 1991. Multiple modes of engrailed regulation in the progression towards cell fate determination. Nature 352: 404 410 .

Han, K., M. Levine, and J. Manley. 1989. Synergistic activation and repression of transcription by Drosophila homeobox proteins. Cell 56: 573-583.

Hiromi, Y. and W.J. Gehring. 1987. Regulation and function of the Drosophila segmentation gene fushi tarazu. Cell 50: $963-974$.

Hoey, T. and M. Levine. 1988. Divergent homeobox proteins recognize similar sequences in Drosophila. Nature 332: 858-861.

Ingham, P. 1988. The molecular genetics of embryonic pattern formation in Drosophila. Nature 335: 25-34.

Ingham, P. and P. Gergen. 1988. Interactions between the pairrule genes runt, hairy, even-skipped and fushi tarazu and the establishment of periodic pattern in the Drosophila embryo. Development 104 (Suppl.): 51-60.

Ingham, P., N. Baker, and A. Martinez-Arias. 1988. Regulation of segment polarity genes in the Drosophila blastoderm by fushi tarazu and even-skipped. Nature 331: 73-75.

Jaynes, J.B. and P.H. O'Farrell. 1988. Activation and repression of transcription by homeodomain-containing proteins that bind a common site. Nature 336: 744-749.

Jiang, J., T. Hoey and M. Levine. 1991. Autoregulation of a segmentation gene in Drosophila: Combinatorial interaction of the even-skipped homeo box protein with a distal enhancer element. Genes \& Dev. 5: 265-277.

Krause, H.M., R. Klemenz, and W.J. Gehring. 1988. Expression, modification and localization of the fushi tarazu protein in Drosophila embryos. Genes \& Dev. 2: 1021-1036.

Lawrence, P. and P. Johnston. 1989. Pattern formation in the Drosophila embryo: Allocation to parasegments by evenskipped and fushi tarazu. Development 105: 761-767.

Lawrence, P., P. Johnston, P. MacDonald, and G. Struhl. 1987. Borders of parasegments in Drosophila embryos are delimited by the fushi tarazu and even-skipped genes. Nature 328: $440-442$.

MacDonald, P.M., P. Ingham, and G. Struhl. 1986. Isolation, structure, and expression of even-skipped: A a second pairrule gene of Drosophila containing a homeobox. Cell 47: 721-734.

Martinez-Arias, A., N. Baker, and P. Ingham. 1988. Role of segment polarity genes in the definition and maintenance of cell fates in Drosophila. Development 103: 157-170.

Nüsslein-Volhard, N. and E. Wieschaus. 1980. Mutations affecting segment number and polarity in Drosophila. Nature 287: 795-801.

Nüsslein-Volhard, C., H. Kluding, and G. Jürgens. 1985. Genes affecting the segmental subdivision of the Drosophila embryo. Cold Spring Harbor Symp. Quant. Biol. 50: 145-154.

Okhuma, Y., M. Horikoshi, R. Roeder, and C. Desplan. 1990. Binding site-dependent direct activation and repression of in vitro transcription by Drosophila homeodomain proteins. Cell 61: 475-484.

Pankratz, M.J. and H. Jäckle. 1990. Making stripes in the Drosophila embryo. Trends Genet. 6: 287-292.

Struhl, G. 1985. Near-reciprocal phenotypes caused by inactivating or indiscriminate expression of the Drosophila segmentation gene $f t z$. Nature 318: 677-680.

1989. Differing strategies for organizing anterior and posterior body patterns in Drosophila embryos. Nature 338: 741-744.

Tan, S. and J.R. Richmond. 1990. DNA binding-induced conformational change of the yeast transcriptional activator PRTF. Cell 62: 367-377.

Wieschaus, E. and C. Nüsslein-Volhard. 1986. Looking at embryos. In Drosophila: A practical approach (ed. D.B. Roberts), pp. 199-228. IRL Press, Oxford, England.

Winslow, G.M., H. Shigeo, M. Krasnow, D.S. Hogness, and M.P. Scott. 1989. Transcriptional activation by the Antennapedia and fushi tarazu proteins in cultured Drosophila cells. Cell 57: 1017-1030. 


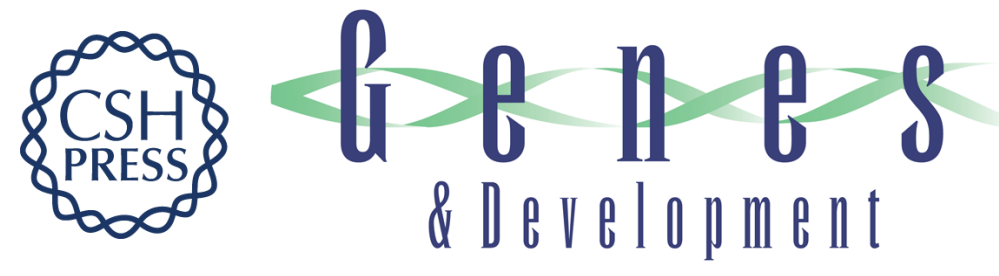

\section{Concentration-dependent activities of the even-skipped protein in Drosophila embryos.}

A S Manoukian and H M Krause

Genes Dev. 1992, 6:

Access the most recent version at doi:10.1101/gad.6.9.1740

References This article cites 35 articles, 9 of which can be accessed free at:

http://genesdev.cshlp.org/content/6/9/1740.full.html\#ref-list-1

License

Email Alerting

Service

Receive free email alerts when new articles cite this article - sign up in the box at the top right corner of the article or click here.

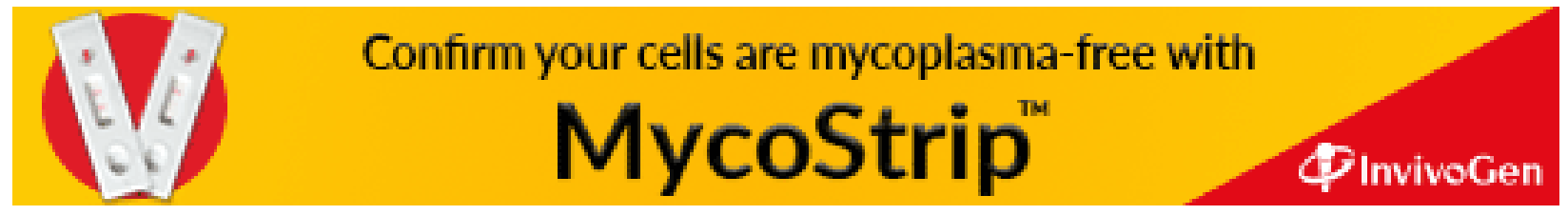

